\title{
IDEOLOGI PESANTREN SALAF: DERADIKALISASI AGAMA DAN BUDAYA DAMAI
}

\author{
Syamsul Ma'arif \\ IAIN Walisongo Semarang, Jl. Walisongo 3-5 Jrakah Semarang \\ E-mail: syamsulmaarif1974@yahoo.co.id \\ HP. +62-81325412790
}

\begin{abstract}
The emergence of a number of religious sects which culminated in violence, especially in Indonesia sometimes dragging the name of the salaf pesantren, is actually a phenomenon that is motivated by a number of determinant factors, such as economic factors, politics and ideology. For the first and second factor has been widely discussed by experts/ researchers, while the ideological factor often forgotten by many people. Whereas the issue of ideologythat believed by each religious groups usually determine their direction and purpose. In fact, sometimes leads to an attitude/decision how to look to other groups. The streams of radical ideology has encourages the hostility with the others. This phenomenon of course reversed with the mainstream ideology of pesantren salaf, one of which is a Pesantren Edimancoro Salatiga. as the result of research revealed that the idiology of this pesantren salaf, always talking mutual respect and love for fellow human beings, voice for justice, liberation and against any anarchism is an enemy of every religion.
\end{abstract}

Abstract: Penetrasi global dan berubahnya dunia telah menyeret sebagian dari komunitas pesantren untuk bersikap ekslusif, radikal dan bahkan melakukan tindakan kekerasan atas nama agama melawan simbol-simbol Barat. Pesantren dengan ekspresi positif dengan menekankan akan sikap toleran, moderat dan damai. Pesantren Edi Mancoro juga telah mencoba melakukan inisiatif pada perjumpaan antarbudaya dan iman. Dalam perspektif pesantren, Edi Mancoro sesungguh implementasi semua bentuk perbedaan, jika dipandang sebagai modal untuk melakukan "perubahan". Kiai dan pengasuh Pondok Pesantren Edi Mancoro telah melakukan reformasi kurikulum pesantren, dengan menekankan pada upaya rekontruksi, pada konteks ke-Indonesia-an, dengan mempertimbangkan kondisi masyarakat yang sedemikian plural, baik agama, etnis, maupun kepercayaan.

Kata Kunci: Ideologi, Pesantren Salaf, Deradikalisasi, dan Budaya Damai. 


\section{A. Pendahuluan}

Istilah salaf yang sering dilekatkan kepada pesantren tradisional di Indonesia selalu berorientasi lama (tradisional) dan terdiri dari kelompok tua (Woodward, 2012: 120). Pesantren salaf selalu mempertahankan nilai-nilai ortodoksi Islam dalam sistem pendidikan pesantren dengan cara melakukan usaha-usaha untuk melestarikan tradisi ulama salaf (Ismail, 1997: 110). Kandungan intelektualnya berkisar pada paham akidah Asy'ari, mazhab fiqih Syafi'i (dengan sedikit menerima tiga madzhab lain) dan ajaran-ajaran akhlaq dan tasawwuf al-Ghazāli (Bruinessen, 1995: 19). Dari awal munculnya lebih menekankan pada karakter moral dan indigenous budaya lokal Jawa serta selalu mentransmisikan wajah Islam yang inklusif dan menebarkan kedamaian di muka bumi (rahmat li al-'alamīn). Tetapi sayang, belakangan ini dengan munculnya sejumlah kekerasan agama di Indonesia yang kebanyakan dilakukan oleh beberapa santri yang mengaku alumni dari beberapa pesantren salaf. Istilah salaf ini kemudian beralih arti dan cenderung bermakna pejoratif sebab masyarakat kemudian sering menyalahartikan, menggeneralisasikan, dan selalu mencurigai pesantren salaf sebagai "sarang teroris".

Pendek kata, makna penting membicarakan dan mengetahui ideologi pesantren salaf di Indonesia agar tidak akan lagi salah tafsir mengenai lembaga yang sudah berumur ratusan tahun ini dan menurut penilaian Zuhri (2010: 30) pesantren mainstream telah terbukti mempunyai kontribusi bagi NKRI. Pesantren dilahirkan untuk memberikan respon terhadap situasi dan kondisi sosial suatu masyarakat yang tengah dihadapkan pada runtuhnya sendi-sendi moral melalui transformasi nilai yang ditawarkanya (amar ma'rüf nahy munkar). Misi pendirian pesantren adalah menyebarluaskan informasi ajaran universalitas Islam ke seluruh pelosok Nusant ara yang berwatak pluralis. Dengan demikian, menggeneralisasikan pesantren sebagai sarang teroris dan penyebar paham radikalisme dan terorisme (sebagaimana sebuah penilaian yang berkembang pada saat ini) - sesungguhnya adalah tindakan "gegabah" dan berlawanan dengan kenyataan dengan nilai-nilai dan tradisi yang berkembang di pesantren. Apalagi dalam realitas sejarahnya, pesantren telah mengalami dinamika perkembangan yang pesat, lebih-lebih terkait modernisasi dan respon terhadap Barat tersebut. Mainstream yang dikembangkannya pun cenderung akomodatif dengan menerima nilai-nilai baru yang dianggap lebih baik dan mempertahankan tradisi masa lampau sebagai karakter uniknya. 


\section{B. Seputar Makna Radikalisme}

Memang telah terjadi simpang siur pendefinisian tentang makna fundamentalisme, radikalisme dan terorisme - yang semua ini sebetulnya merupakan terminologi dari Barat dan telah menjadi salah satu isu santer di beberapa negara termasuk Indonesia. Implikasinya juga luar biasa, bahkan telah menyebabkan konflik internal dan pengkotak-kotakan dalam beragama. Tudingan dengan bahasa-bahasa tersebut juga sempat menimpa lembaga tertua di Indonesia, yang selama ini sangat terkenal dengan prinsip-prinsipnya yang sangat toleran, inklusif, dan moderat.

Padahal, menurut pelacakan sejumlah referensi, sesungguhnya istilah radikalisme lebih menunjukkan pada gerakan kekerasan yang diambil oleh sekelompok golongan akibat respon ketidakpuasan pada realitas politik dan sosio-historis. Makna radikalisme, secara etimologis dalam bahasa Arab sering disebut dengan istilah tatarruf dan bersinonim dengan istilah ifrat (keterlaluan) atau ghuluw (melampaui batas). Kata "radikal", dalam Dictionary of American History, lebih popular digunakan untuk menunjukkan individu, partai, dan gerakan yang berkeinginan merubah keberadaan sesuatu praktik, institusi, atau sistem sosial secara cepat. Dalam politik, "radikal" sering digunakan untuk seseorang dan sebuah partai yang merefleksikan pandangan kelompok kiri (Markowitz, 2003). Dengan demikian, penggunaan istilah radikalisme dalam bahasa sehari-hari lebih menunjukkan arti kelompok kiri, kekerasan, ekstremis dan revolusi.

Adapun menurut terminologi, radikalisme ialah sebuah paham atau aliran yang sering berpandangan kolot, bertindak dengan menggunakan kekerasan dan bersifat ekstrem untuk merealisasikan cita-citanya. Hal ini didasarkan pada pengertian yang bersumber dari beberapa referensi. Pertama, Ensiklopedi Indonesia yang mengartikan radikalisme dengan semua aliran politik, yang para pengikutnya menghendaki konsekuensi yang ekstrem, setidak-tidaknya konsekuensi yang paling jauh dari pengejawantahan ideologi yang mereka anut (Sadily, 1984). Kedua, dalam Kamus Besar Bahasa Indonesia (1995), yang menjelaskan radikalisme adalah paham atau aliran yang menginginkan perubahan atau pembaharuan sosial dan politik dengan cara kekerasan atau drastis. Ketiga, radikalisme adalah gerakan yang berpandangan kolot dan sering menggunakan kekerasan dalam mengajarkan keyakinan mereka (Nasution, 1995: 124).

Secara historis, radikalisme agama terdiri dari dua bentuk. Pertama, radikalisme dalam pikiran (yang sering disebut sebagai fundamentalisme). Kedua, 
radikalisme dalam tindakan (disebut terorisme). Radikalisme yang bermetamorfosis dalam tindakan yang anarkis biasanya menghalalkan cara-cara kekerasan dalam memenuhi keinginan atau kepentingan.

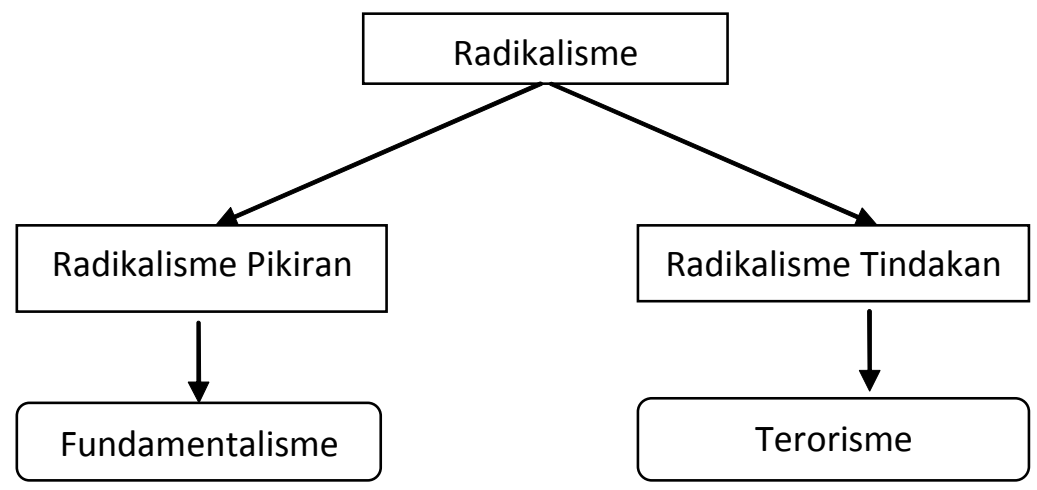

Gambar: dua bentuk radikalisme

Untuk kasus radikalisme pikiran karena masih pada tataran filosofis paradigmatik, tentu tidak menjadi masalah karena tidak mengakibatkan kerusakan peradaban manusia, meskipun juga perlu diwaspadai dan kalau bisa dijauhkan dari generasi kita. Meskipun bersifat pemikiran biasanya bisa menimbulkan "masalah" pada saat komunikasi dan bergaul dengan masyarakat luas. Terlebih lagi, radikalisme yang bersifat praksis, sudah harus dilenyapkan dimuka bumi demi harmonisasi dunia. Untuk memudahkan tipologi radikalisme agama yang berarti pemikiran atau sikap keagamaan seseorang tersebut, meminjam kerangka teoritis seorang sosiolog agama, Marty, gejala radikalisme dapat dicirikan dengan beberapa hal; pertama, oppositionalism (faham perlawanan). Perlawanan terhadap segala sesuatu yang dianggap membahayakan eksistensi agama mereka. Kedua, penolakan hermeneutika, yakni menolak sikap kritis terhadap teks dan interpretasinya. Ketiga, penolakan terhadap pluralism dan relativisme (Marty, 1992: 3-13).

Kelompok gerakan Islam yang masuk pada katagori radikalisme, biasanya melawan pada pemerintahan yang ada karena dianggap telah menerapkan prinsip hukum yang salah dan kafir yaitu sekular. Sebagaimana prinsip demokrasi yang telah diterapkan dan dianut Indonesia adalah sistem kafir yang tidak menunjukkan sedikit pun keislamanan di dalamnya. Mereka beranggapan terdapat perbedaan yang sangat mendasar antara demokrasi dan Islam. Sebab, dalam demokrasi kekuasaan penuh terletak dengan manusia sedangkan Islam kekuasaan mutlak berada pada Allah (Zada, 2002: 137). 
Bagi mereka, hukum yang benar hanya satu, yakni syari'at Islam. Selain agung, syariat Islam tidak bisa ditandingi oleh undang-undang sekular. Oleh karena itu, mereka senantiasa menyerukan pemberlakuan syari'at Islam secara kāffah oleh negara apabila Indonesia berkeinginan keluar dari semua masalah yang sedang melilitnya dan menjadi negara yang adil dan sejahtera serta baldatun tayyibatun wa rabbun ghafür.

Radikalisme tentu saja berbeda dengan fundamentalisme. Fundamentalisme biasanya dalam bahasa Arab disebut dengan uṣūliyyah berasal dari kata ushul, yang merujuk pada prinsip-prinsip dasar yurisprudensi Islam (uṣūl fiqih) (Amstrong, 2005: 137). Seorang fundamentalis berarti adalah seorang yang mendasar atau lebih tepatnya keinginan mengembalikan segala sesuatu kepada asal pokoknya - dalam konteks Islam kembali kepada sumber hukum yaitu alQur'an dan al-Hadist.

Fundamentalisme adalah sebuah ideologi yang menjadikan agama sebagai pandangan hidup oleh masyarakat at aupun individu (Afadlal, dkk. 2005). Kata fundamentalisme berbeda dengan traditionalism (Watt, 1988), tetapi memiliki sebuah hubungan. Posisi agama oleh kaum fundamentalis dicirikan dengan ketaatan kaku terhadap apa yang dirasakan sebagai sesuatu yang sangat dasar, sebuah prinsip tradisi dan kepercayaan dari agama.

Istilah fundamentalisme masuk dalam ilmu sosial pada dua abad yang lalu sebagai sebuah bentuk umum dari keagamaan ortodok revivalis konservatif. Meskipun aslinya, fundamentalisme hanya dihubungan dengan agama Kristen dan kemudian istilah tersebut menjadi berkembang untuk menunjukkan tradisi kebudayaan agama lain pada saat revolusi Iran pada 1978-79. Sekarang ini, istilah itu digunakan untuk menggambarkan agama Kristen Evangelis, revolusi Iran, Yahudi Ultra-Ortodox, Sikh Militan, dan para pejuang agama Buddha di antara agama-agama lain. Secara spesifik, munculnya istilah fundamentalisme ini berasal dari sebuah gerakan keagamaan di permulaan abad duapuluh. Namanya berasal dari sebuah buku yang berjudul: The Fundamentals: A Testimony of the Truth, dipublikasikan pada tahun 1910 dan 1915.

Gerakan fundamentalisme biasanya berkeinginan mengembalikan masyarakat kepada dasar-dasar agama yang kuat dalam menjalani kehidupan di dunia. Pada konteks ini fundamentalisme memiliki makna positif, tapi biasanya fundamentalisme selalu beriringan dengan radikalisme terlebih-lebih jika kebebasan beragama terhalang oleh situasi social politik yang ada di masyarakat dan tidak tercapainya harapan mereka.

Semua fundamentalisme agama yang ada di dunia ini memiliki kesamaan visi keduniaan dan etos. Visinya adalah menempatkan Tuhan dan ayat-ayat 
sucinya, di samping perlawanan antara yang baik dan nista, pada pusat perhatian individu dan kelompok. Etosnya adalah proses minoritas atau kekesalan terhadap pergantian progesif agama dari satu institusi ke institusi lain di suatu masyarakat yang semakin tersekulerisasi (Antoun, 2003: 39). Dalam konteks Fundamentalisme Islam, gerakan yang sering diwacanakan adalah mengangankan kehidupan Islam di era klasik kembali berjaya pada konteks dunia modern. Kemunculannya bisa dikatakan sebagai akibat sikap kecewa terhadap modernisasi. Semua yang berbau Barat sebagai tempat penyemaian gagasan modernisme selalu ditentang dan dilawan dengan segala cara, termasuk dengan kekerasan.

Wajar jika fundamentalisme dan radikalisme dalam perspektif Barat sering dikaitkan dengan sikap ekstrem, kolot, stagnasi, konservatif, anti-Barat, dan keras dalam mempertahankan pendapat bahkan dengan kekerasan fisik. Penggunaan istilah radikalisme atau fundamentalisme bagi umat Islam sebenarnya tidak tepat karena gerakan radikalisme itu tidak terjadi di setiap negeri Muslim dan tidak dapat ditimpakan kepada Islam. Radikalisme merupakan gerakan yang dilakukan oleh individu atau kelompok yang dirugikan oleh fenomena sosio-politik dan sosiohistoris.

Lebih-lebih jika gerakan fundamentalisme digerakkan atas sebuah keimanan. Iman dipahami sebagai kecintaan kepada Allah SWT. Kecintaan kepada sang pencipta adalah kecintaan kepada makhluknya (Syuaibi, 2004: 147). Adapun kekerasan yang dipakai oleh fundamentalisme yang selalu mengedepankan kekerasan dan permusuhan adalah sangat jauh dengan nilai-nilai keimanan itu sendiri.

\section{Pesantren dan Deradikalisasi Agama: Fenomena Pesant- REN EDI MANCORO}

\section{Sekilas Pesantren Edi Mancoro}

Pesantren Edi Mancoro atau sering disebut dengan Wisma Santri Edi Mancoro terletak $15 \mathrm{~km}$ arah selatan dari Kota Bawen, Kabupaten Semarang, tepatnya berada di Dusun Bandungan, Desa Gedangan Rt.02/I Kec. Tuntang Kab. Semarang, Jawa Tengah, Telp. (0298) 313 329. Pesantren ini, menempati tanah seluas $3.000 \mathrm{~m} 2$. Saat diresmikan, pesantren ini memilki enam bangunan yang dikelilingi ribuan pohon salak pondoh yang rimbun, hingga mengalami perkembangan yang sangat pesat seperti sekarang.

Rute menuju Pondok Pesantren Edi Mancoro, tidaklah terlalu sulit meskipun berada di daerah pedesaan yang terpencil dengan hawa dingin, sepi dan 
sunyi. Jarak tempuh dari kota semarang menuju daerah pondok di kota Salatiga tersebut, dengan mengendarai mobil hampir memerlukan waktu \pm 2 jam dengan kecepatan normal. Setelah tiba di Pasar Jetis Salatiga, kita akan menemukan perempatan lampu merah dan pos polisi kemudian belok kanan lurus. Setelah menempuh jarak empat kilometer atau sekitar 30 menit, tibalah di pondok pesantren tersebut yang berada di kanan jalan dan di pintu gerbang terpampang nama "Wisma Santri Edi Mancoro".

Sebelum berdiri menjadi sebuah pesantren memang Pesantren Edi Mancoro berawal dari Yayasan Desaku Maju (YDM). Sebuah Yayasan yang sengaja digunakan KH. Mahfud Ridwan untuk menyemaikan semua cita-citanya. Semenjak dia pulang mengembara mencari ilmu dari Baghdad, Irak, pada 1970, KH. Mahfudz Ridwan banyak menghabiskan waktu di YDM ini.

Inspirasi membentuk yayasan tersebut berawal dari saran teman beliau KH. Abdurrahman Wahid (Gus Dur) yang pada saat itu Gus Dur belum menjadi presiden dan masih aktif di LP3S. Pada tahun 1979, atas desakan teman beliau yang bernama KH. Zubeir, terbentuklah sebuah LSM yang bergerak di bidang pemberdayaan masyarakat. Menurut pengakuan KH. Mahfudz Ridwan (Wawancara, 2013) "Yayasan tersebut secara historis didirikan oleh para aktivis era 80-an antara lain KH. Mahfudz Ridwan, Lc., KH. Muhammad HM. Sholeh, BA., Matori Abdul Jalil, Zainal Arifin, BA., serta Ali Tahsisudin, BA”. Dilalah kersaning ngalah, masih menurut pengakuan beliau, LSM itu banyak dukungan dari dalam dan luar negeri. Bahkan pada tahun 1985-an memperoleh bantuan sebanyak 33 juta dari USAID untuk program sanitasi air bersih di 13 pesantren dan bantuan dari Asia Oxford untuk pelatihan-pelatihan dan membentuk koperasi sejahtera.

Menelisik visi dan misi Pesantren Edi Mancoro adalah membentuk santri yang berwawasan keagamaan secara mendalam, juga berwawasan kebangsaan, kemasyarakatan dalam konteks keindonesiaan yang plural. Di samping membentuk santri yang peduli serta berkemampuan untuk mendampingi masyarakat secara luas. Lahirnya pesantren dengan visi misi tersebut karena didorong kepedulian kiai Mahfudz Ridwan terhadap realitas kemajemukan bangsa Indonesia yang harus dijaga dan dilestarikan kebudayaannya. Di samping semakin banyaknya pengangguran, tidak hanya oleh mereka yang tidak sekolah tapi jebolan perguruan tinggi juga banyak yang menganggur. "Saya mengetahui persis kondisi kawan-kawan mahasiswa", kata kiai. KH. Mahfudz Ridwan yang pernah mengajar di STAIN sejak 1972. Wajar jika dia tahu persis kualitas mahasiswa yang masuk STAIN. Harapan KH. Mahfudz Ridwan, mereka belajar 
lebih dini, memiliki nilai tambah dalam belajar, daripada mereka yang ada di pondok pesantren. Setelah lulus dari perguruan tinggi, karena sebagai santri sering mengadakan latihan, dia langsung memiliki keterampilan dan bisa mendampingi masyarakat. Tugasnya memandirikan masyarakat, dan menciptakan lapangan pekerjaan bagi masyarakat di sekitarnya.

\section{Sifat dan Program Pesantren}

Program yang diselenggarakan Pesantren Edi Mancoro bertujuan untuk merealisasikan gagasan besar pendok pesantren transformatif. Bisa dikatakan program adalah "ruh" yang menggerakkan dari sebuah lembaga pendidikan termasuk pesantren ini. Apalah jadinya sebuah pesantren yang megah dengan visi misi yang melangit, tapi tidak didukung dengan program yang bagus pastilah lama kelamaan akan layu dan mati.

Oleh karena itu, agar tetap hidup dan dinamis Pesantren Edi Mancoro mendesain sebuah program. Menurut salah satu pengurus pesantren yang sering disebut "lurah pondok" menuturkan pada peneliti, sesungguhnya di pesantren ini memiliki banyak aktivitas dan disesuaikan dengan tingkatan kelas. Di pesantren ini terdapat lima kelas, untuk kelas 1 dan 2 sehabis maghrib biasanya mengaji kitab kuning di aula. Selain itu, juga ada kegiatan belajar bersama seminggu sekali yang diikuti semua santri. Mereka berkumpul menurut kelompok usia. Beberapa pelajaran, di antaranya, membaca selawat, berlatih khotbah, musyawarah dan diskusi, serta belajar qirā'ah.

Semua program yang dilaksanakan pesantren adalah dalam rangka pemahaman ajaran agama, di samping kerja-kerja pemberdayaan masyarakat, berikut gambaran dari program-program yang disediakan Pesantren Edi Mancoro:

a. Melakukan kajian dan studi keislaman secara intensif dan berkesinambungan, baik dalam perspektif tekstual yang bersifat normatif maupun dalam perspektif kontekstual keindonesiaan.

b. Menyelenggarakan diskusi-diskusi ilmiah, dialog-dialog keagamaan, dialog kemasyarakatan lintas SARA bagi seluruh komponen masyarakat Indonesia yang plural.

c. Melakukan sosialisasi sekaligus pribumisasi atas hasil kajian-kajian di atas bagi komunitas masyarakat pada umumnya.

d. Menyelenggarakan diklat, loklat, kursus kilat (short course) bagi aktivis pesantren dan aktivitas kemasyarakatan dalam rangka pemberdayaan masyarakat. 
e. Membentuk jaringan kerja sama antar pesantren, institusi kemasyarakatan, organiasasi sosial kemasyarakatan, seluruh komunitas strategis di masyarakat, dalam rangka kerja-kerja pemberdayaan masyarakat.

\section{Deradikalisasi Agama}

Meskipun banyak pihak menuding keberadaan pesantren sebagai sumber dari ekstremisme dan radikalisme belakangan ini, tidaklah kemudian direspon oleh Pesantren Edi Mancoro secara emosional dan apologis. Semua tudingan itu sebagaimana penjelasan KH. Mahfud Ridwan dikarenakan minimnya pengetahuan mereka akan keberadaan pesantren dan memang pada kenyataan masih terdapat sejumlah pesantren yang masih menggunakan metode konvensional dan cenderung indoktrinatif dalam mengajarkan ilmu agama pada para santrinya. Semua itu harus dijadikan bahan evaluasi dan perbaikan demi kemajuan pesantren ke depan.

Melihat pesantren tidak boleh sepenggal, menyimak pesantren adalah laksana masuk ke hutan belantara. Pesantren mempunyai wajah yang multidimensi dan kaya akan khazanah-khazanah yang sulit untuk dituangkan dalam teks yang bisa dibaca oleh setiap orang-orang. Sampai-sampai ada suatu guyonan bahwa agen intelijen sekelas CIA yang memiliki reputasi internasional serta mempunyai sistem kerja yang canggih sekalipun acapkali sulit menyadap informasi yang ada di pesantren gara-gara setiap kali rapat tidak ada nominasinya (wawancara dengan KH.Mahfud Ridwan, 2013). Wajar jika banyak tuduhan jelek yang dialamatkan di pesantren adalah "salah alamat". Seperti banyak perspektif yang mengatakan pesantren sebagai lembaga pendidikan yang tradisional, klasik dan apa adanya. Bahkan, sebagai lembaga pendidikan agama Islam yang dituding sebagai mendoktrin sikap kekerasan pada para santrinya. Padahal, pesantren sangat berperan besar dalam menjaga gempuran arus globalisasi yang kian menggila dan hedonisme masyarakat yang kian meningkat.

Pengasuh Pesantren Edi Mancoro menilai sesungguhnya tudingan miring terhadap pesantren semacam itu, bukan tanpa sebab. Pada realitasnya, terdapat sejumlah pesantren di Indonesia yang dari segi materi dan metodologi pengajarannya masih mengajarkan kebencian kepada orang lain yang tidak seagama. "Memang perlu ada semacam reformasi ke arah proses belajar mengajar yang humanis dan toleran di pesantren", kata beliau. Biar fair dan imbang dalam menilai pesantren, memang kita tidak boleh terjebak dalam romantisme sejarah egois yang menggiurkan. Kita harus tetap melakukan kritik dan autokritik terhadap pesantren itu. Sebagai sebuah entitas masyarakat yang strategis, 
pesantren justru gagal dalam mengemban misi perubahan bagi masyarakat yang ada di sekitarnya. Pesantren hadir seolah-olah sebagai sebuah bangunan tua yang berdiri "diam" dengan aroma kewibawaannya.

\section{Membangun Kultur Damai}

Lebih dari itu, sesungguhnya yang perlu ditampilkan oleh pesantren adalah sebuah ajaran yang berprinsip pada fundamental Islam sebagai rahmatan li al'alamīn. Implikasi dari konsep ini sesungguhnya pesantren tidak mengenal budaya kekerasan, menurut salah seorang santri Edi Mancoro (2013). Budaya yang dikenal pesantren adalah budaya santun, kasih sayang dan menghornati perbedaan.

Sebagaimana penuturan beberapa santri, Pesantren Edi Mancoro sering mengajarkan para santrinya untuk saling menghormati antarsesama manusia dengan saling mengenal dan berbagi pengalaman. Bahkan, di pondok ini sering dilakukan kegiatan Forum Lintas Iman Muda. Menurut pengakuan sejumlah santri, forum itu biasanya diisi diskusi tentang berbagai persoalan sosialkeagamaan, atau terkadang hanya makan siang bersama dengan tujuan untuk mengakrabkan peserta sekaligus mengenalkan budaya pesantren seperti menyajikan makanan dengan cara koron. Tradisi khas pesantren yang berarti makan bersama dalam satu piring atau loyang.

Oleh karena itu, pesantren ini sering kedatangan para tamu, baik dari dalam maupun luar negeri dengan berbagai latarbelakang etnis, agama dan budaya. Mereka biasanya pingin mengenal Islam dari dekat. Sebelum berkumpul dan berinteraksi dengan para santri Edi Mancoro, terutama tamu yang berasal dari luar negeri pada umumnya masih beranggapan bahwa Islam adalah agama kekerasan dan jihad sebagaimana agama yang sering diberitakan di sejumlah pemberitaan Barat. Berkat mereka mempelajari Islam di Pesantren Edi Mancoro, dengan berinteraksi, bergaul, makan, bahkan tidur bersama dengan para santri. Akhirnya image negatif tentang pesantren sebagai sarang teroris lambat laun menjadi sirna.

\section{Simpulan}

Penetrasi global dan berubahnya dunia telah menyeret sebagian dari komunitas pesantren untuk bersikap ekslusif, radikal dan bahkan melakukan tindakan kekerasan atas nama agama melawan simbol-simbol Barat. Pesantren dengan ekspresi positif dengan menekankan akan sikap toleran, moderat dan damai. Pesantren Edi Mancoro juga telah mencoba melakukan inisiatif pada perjumpaan antarbudaya dan iman. Dalam perspektif pesantren, Edi Mancoro 
sesungguh implementasi semua bentuk perbedaan, jika dipandang sebagai modal untuk melakukan "perubahan". Kiai dan pengasuh Pondok Pesantren Edi Mancoro telah melakukan reformasi kurikulum pesantren, dengan menekankan pada upaya rekonstruksi, pada konteks ke-Indonesia-an, dengan mempertimbangkan kondisi masyarakat yang sedemikian plural, baik agama, etnis, maupun kepercayaan. Ideologi yang dijadikan pegangan Edi Mancoro senantiasa diselaraskan dengan kepentingan jaman yang membangun damai dan menentang ajaran prinsip agama yang bersifat ekstremisme, radikalisme, dan terorisme. Meskipun pendidikan agama di pesantren ini bersifat dinamis dan sesuai dengan perkembangan zaman, namun masih dalam koridor syari'at Islam dan tidak menyalahi sunnahnya.

\section{Daftar Pustaka}

Afadlal, dkk. 2005. Islam dan Radikalisme. Jakarta: LIPI Press.

Clifford Geertz, 1997. The Interpretation of Cultures. New York: Basic Books. Inc.

Ismail, Faisal. 1997. Paradigma Kebudayaan Islam: Studi Kritis dan Refleksi Historis. Yogyakarta: Titian Ilahi Press.

Syuaibi, Gils Kibil Ali. 2004. Meluruskan Radikalisme Islam. Ciputat: Pustaka Azhary.

Nasution, Harun. 1995. Islam Rasional. Bandung: Mizan.

Sadily, Hasan (Pemred). 1984. Ensiklopedi Indonesia. Ikhtiar Baru-Van Hoeve.

Tim Penyusun. 1995. Kamus Besar Bahasa Indonesia. Jakarta: Balai Pustaka, Edisi Kedua.

Amstrong, Karen. 2005. "Islam: A short History” diterj. oleh Fungky Kusnaedy Timur. Yogyakarta: Jendela.

Khamami Zada, Islam Radikal, (Jakarta:Teraju, 2002), Cet. I.

Woodward, Mark R. 2012. Islam Jawa: Kesalehan Normatif versus Kebatinan. Yogyakarta: LKiS.

Marty, Martin E. 1992. "What is Fundamentalism? Theological Perspective" dalam Kung dan Moltmann (Eds), Fundamentalism as a Ecunemical Challenge London: tp.

van Bruinessen, Martin. 1995. Kitab Kuning Pesantren dan Tarekat. Bandung: Mizan. 
Norman Markowitz, "Radical and Radicalisme" dalam (Dictionary of American History, 2003). http://www.encyclopedia.com.

Antoun, Ricard T. 2003. Memahami Fundamentalisme. Surabaya: Pustaka Eureka.

Zuhri, Saifudin. 1999. "Pendidikan Pesantren di Persimpangan Jalan" dalam Marzuki Wahid,dkk. Pesantren Masa Depan Wacana Pemberdayaan dan Transformasi Pesantren. Bandung: Pustaka Hidayah.

Syamsul Ma'arif. 2001. "Dinamika Pesantren Kontemporer” dalam Millah Jurnal Studi Agama, Vo. XI, No. 1, Agustus 2001. Yogyakarta: UII.

Thompson, J.B. 1990. Idiology and Modern Culture. California: Stanford University Press.

Watt, W.M. 1988. Islamic Fundamentalism and Modernity. London: Routledge. William O. Beeman. 2001. "Fighting the Good Fight: Fundamentalism and Religion Revival” dalam J. MacClancy, Ed. 2001. Antropology for the Real World. Chicago: University of Chicago Press.

Yusuf, Choirul dan Suwito NS. 2009. Model Pengembangan Ekonomi Pesantren. Purwokerto: STAIN Press. 